\title{
Prognostic and Immunological Significance of ARID1A Status in Endometriosis-Associated Ovarian Carcinoma
}

\section{Short title: Significance of ARID1A Status in EAOC}

\section{Authors}

Karolin Heinze* ${ }^{1,2}$, Tayyebeh M. Nazeran*2, Sandra Lee ${ }^{3}$, Pauline Krämer ${ }^{1,4}$, Evan S. Cairns ${ }^{1}$, Derek S. Chiu ${ }^{2}$, Samuel C.Y. Leung ${ }^{2}$, Eun Young Kang ${ }^{3}$, Nicola S. Meagher ${ }^{5,6}$, Catherine J. Kennedy ${ }^{7,8}$, Jessica Boros ${ }^{7,8}$, Friedrich Kommoss ${ }^{9}$, Hans-Walter Vollert ${ }^{10}$, Florian Heitze $^{11}$, Andreas du Bois ${ }^{11}$, Philipp Harter ${ }^{11}$, Marcel Grube ${ }^{1,4}$, Bernhard Kraemer ${ }^{4}$, Annette Staebler ${ }^{12}$, Felix K.F. Kommoss ${ }^{13}$, Sabine Heublein ${ }^{14}$, Hans-Peter Sinn ${ }^{13}$, Naveena Singh $^{15}$, Angela Laslavic ${ }^{16}$, Esther Elishaev ${ }^{17}$, Alex Olawaiye ${ }^{16}$, Kirsten Moysich ${ }^{18}$, Francesmary Modugno $^{16}$, Raghwa Sharma ${ }^{19,20,21}$, Alison H. Brand ${ }^{8,20}$, Paul R. Harnett ${ }^{8,22}$, Anna DeFazio ${ }^{7,8,20,23}$, Renée T. Fortner ${ }^{24}$, Jan Lubinski ${ }^{25}$, Marcin Lener ${ }^{25}$, Aleksandra Tołoczko-Grabarek $^{25}$, Cezary Cybulski ${ }^{25}$, Helena Gronwald ${ }^{26}$, Jacek Gronwald ${ }^{25}$, Penny Coulson $^{27}$, Mona A El-Bahrawy ${ }^{28}$, Michael E. Jones ${ }^{27}$, Minouk J. Schoemaker ${ }^{27}$, Anthony J. Swerdlow $^{27,29}$, Kylie L. Gorringe ${ }^{30,31}$, Ian Campbell ${ }^{30,32}$, Linda Cook ${ }^{33}$, Simon A. Gayther ${ }^{34}$, Michael E. Carney ${ }^{35}$, Yurii B. Shvetsov ${ }^{36}$, Brenda Y. Hernandez ${ }^{36}$, Lynne R. Wilkens ${ }^{36}$, Marc T. Goodman ${ }^{37}$, Constantina Mateoiu ${ }^{38}$, Anna Linder ${ }^{38}$, Karin Sundfeldt ${ }^{38}$, Linda E. Kelemen $^{39}$, Aleksandra Gentry-Maharaj ${ }^{40,41}$, Martin Widschwendter ${ }^{42}$, Usha Menon ${ }^{40}$, Kelly L. Bolton ${ }^{43}$, Jennifer Alsop ${ }^{44}$, Mitul Shah ${ }^{45}$, Mercedes Jimenez-Linan ${ }^{45}$, Paul D.P. Pharoah $^{44,46}$, James D. Brenton ${ }^{47}$, Kara L. Cushing-Haugen ${ }^{48}$, Holly R. Harris ${ }^{48}$, Jennifer A. Doherty $^{49}$, Blake Gilks ${ }^{2}$, Prafull Ghatage ${ }^{50}$, David G. Huntsman ${ }^{1,2}$, Gregg S. Nelson ${ }^{50}$, Anna V. Tinker ${ }^{2,51}$, Cheng-Han Lee ${ }^{52}$, Ellen L. Goode ${ }^{53}$, Brad H. Nelson ${ }^{54}$, Susan J. Ramus ${ }^{5,6}$, Stefan Kommoss ${ }^{4}$, Aline Talhouk ${ }^{1,2}$, Martin Köbel $\square^{3}$ and Michael S. Anglesio $\square^{1,2}$

\section{Affiliations}

1. University of British Columbia, Department of Obstetrics and Gynecology, Vancouver, BC, Canada.

2. University of British Columbia, Vancouver General Hospital, and BC Cancer. British Columbia's Gynecological Cancer Research Team (OVCARE), Vancouver, BC, Canada. 3. University of Calgary, Department of Pathology and Laboratory Medicine, Calgary, AB, Canada.

4. University Hospital Tübingen, Department of Women's Health, Tübingen, Germany. 5. University of New South Wales, Adult Cancer Program, Lowy Cancer Research Centre, Sydney, New South Wales, Australia.

6. University of New South Wales, School of Women's and Children's Health, Sydney, New South Wales, Australia.

7. The University of Sydney, Centre for Cancer Research, The Westmead Institute for Medical Research, Sydney, New South Wales, Australia.

8. Westmead Hospital, Department of Gynaecological Oncology, Sydney, New South Wales, Australia

9. Medizin Campus Bodensee, Institute of Pathology, Friedrichshafen, Germany.

10. Medizin Campus Bodensee, Department of Gynecology and Obstetrics, Friedrichshafen, Germany.

11. Kliniken Essen Mitte, Department of Gynecology and Gynecologic Oncology, Essen, Germany. 
12. University Hospital Tübingen, Institute of Pathology and Neuropathology, Tübingen, Germany.

13. University Hospital Heidelberg, Institute of Pathology, Heidelberg, Germany.

14. University Hospital Heidelberg and National Center for Tumor Diseases, Department of

Obstetrics and Gynecology, Heidelberg, Germany.

15. Barts Health National Health Service Trust, Department of Pathology, London, UK.

16. University of Pittsburgh School of Medicine, Department of Obstetrics, Gynecology, and

Reproductive Sciences, PA, USA.

17. University of Pittsburgh School of Medicine, Department of Pathology, PA, USA.

18. Roswell Park Cancer Institute, Department of Cancer Prevention and Control, Buffalo, NY, USA.

19. Westmead Hospital, Tissue Pathology and Diagnostic Oncology, Sydney, New South Wales, Australia.

20. University of Sydney, Sydney, New South Wales, Australia.

21. Western Sydney University, Sydney, New South Wales, Australia.

22. Westmead Hospital, Crown Princess Mary Cancer Centre, Sydney, New South Wales, Australia.

23. The Daffodil Centre, The University of Sydney, a joint venture with Cancer Council NSW, Sydney, New South Wales, Australia.

24. German Cancer Research Center (DKFZ), Division of Cancer Epidemiology, Heidelberg, Germany.

25. Pomeranian Medical University, Department of Genetics and Pathology, International Hereditary Cancer Centre, Szczecin, Poland.

26. Pomeranian Medical University, Department of Propaedeutics, Physical Diagnostics and Dental Physiotherapy, Szczecin, Poland.

27. The Institute of Cancer Research, Division of Genetics and Epidemiology, London, UK.

28. Imperial College London, Department of Metabolism, Digestion and Reproduction,

Hammersmith Hospital, London, UK.

29. The Institute of Cancer Research, Division of Breast Cancer Research, London, UK.

30. The University of Melbourne, Sir Peter MacCallum Department of Oncology, Melbourne, Australia.

31. Peter MacCallum Cancer Centre, Women's Cancer Program, Melbourne, Australia.

32. Peter MacCallum Cancer Centre, Cancer Genetics Laboratory, Research Division,

Melbourne, Australia.

33. The University of New Mexico, Division of Epidemiology and Biostatistics, Albuquerque, NM, USA.

34. Cedars-Sinai Medical Center, Center for Bioinformatics and Functional Genomics and the Cedars Sinai Genomics Core, Los Angeles, CA, USA.

35. John A. Burns School of Medicine, University of Hawaii, Honolulu, Department of Obstetrics and Gynecology, HI, USA.

36. University of Hawaii Cancer Center, Epidemiology Program, Honolulu, HI, USA.

37. Cedars-Sinai Medical Center, Samuel Oschin Comprehensive Cancer Institute, Cancer

Prevention and Genetics Program, Los Angeles, CA, USA.

38. Sahlgrenska Academy at Gothenburg University, Sahlgrenska Center for Cancer

Research, Department of Obstetrics and Gynecology, Gothenburg, Sweden.

39. Medical University of South Carolina, Hollings Cancer Center and Department of Public Health Sciences, Charleston, SC, USA.

40. University College London, MRC Clinical Trials Unit at UCL, Institute of Clinical Trials \& Methodology, London, UK. 
41.University College London, Department of Women's Cancer, Institute for Women's Health, London, UK.

42. University of Innsbruck, EUTOPS Institute, Innsbruck, Austria.

43. Washington University School of Medicine, Department of Hematology and Oncology, Division of Oncology, St. Louis, MO, USA.

44. University of Cambridge, Centre for Cancer Genetic Epidemiology, Department of Oncology, Cambridge, UK.

45. Addenbrookes Hospital, Department of Histopathology, Cambridge, UK.

46. University of Cambridge, Centre for Cancer Genetic Epidemiology, Department of Public Health and Primary Care, Cambridge, UK.

47. University of Cambridge, Cancer Research UK Cambridge Institute, Cambridge, UK.

48. Fred Hutchinson Cancer Research Center, Program in Epidemiology, Division of Public Health Sciences, Seattle, WA, USA.

49. University of Utah, Huntsman Cancer Institute, Department of Population Health Sciences, Salt Lake City, UT, USA.

50. University of Calgary, Department of Oncology, Division of Gynecologic Oncology, Calgary, AB, Canada.

51. University of British Columbia, Department of Medicine, Vancouver, BC, Canada.

52. University of Alberta, Department of Laboratory Medicine and Pathology, Edmonton, $\mathrm{AB}$, Canada.

53. Mayo Clinic, Department of Health Science Research, Division of Epidemiology, Rochester, MN, USA.

54. Trev \& Joyce Deeley Research Centre, British Columbia Cancer Agency, Victoria, BC, Canada.

* These authors contributed equally to this work.

$\square$ Co-corresponding authors:

Michael S. Anglesio, Department of Obstetrics and Gynecology, University of British Columbia, 2660 Oak Street, Vancouver, BC, Canada. E-mail: m.anglesio@ubc.ca. Phone: 604-875-4111

Martin Köbel, Department of Pathology and Laboratory Medicine, University of Calgary, AB, Canada. E-mail: mkoebel@ucalgary.ca 


\begin{abstract}
ARID1A (BAF250a) is a component of the SWI/SNF chromatin modifying complex, plays an important tumor suppressor role, and is considered prognostic in several malignancies. However, in ovarian carcinomas there are contradictory reports on its relationship to outcome, immune response, and correlation with clinicopathological features. We assembled a series of 1623 endometriosis-associated ovarian carcinomas, including 1078 endometrioid (ENOC) and 545 clear cell (CCOC) ovarian carcinomas through combining resources of the Ovarian Tumor Tissue Analysis (OTTA) Consortium, the Canadian Ovarian Unified Experimental Resource (COEUR), local, and collaborative networks. Validated immunohistochemical surrogate assays for ARIDIA mutations were applied to all samples. We investigated associations between ARID1A loss/mutation, clinical features, outcome, CD8+ tumor-infiltrating lymphocytes (CD8+ TIL), and DNA mismatch repair deficiency (MMRd). ARID1A loss was observed in $42 \%$ of CCOC and $25 \%$ of ENOC. We found no associations between ARID1A loss and outcomes, stage, age, or CD8+ TIL status in CCOC. Similarly, we found no association with outcome or stage in endometrioid cases. In ENOC, ARID1A loss was more prevalent in younger patients $(\mathrm{p}=0.012)$, and associated with MMRd $(\mathrm{p}<0.001)$, and presence of CD8+ TIL $(\mathrm{p}=0.008)$. Consistent with MMRd being causative of ARIDIA mutations, in a subset of ENOC we also observed an association between ARIDIA loss-of-function mutation as a result of small indels ( $\mathrm{p}=0.011$, vs. single nucleotide variants). In ENOC, the association between ARID1A loss, CD8+ TIL, and age, appears confounded by MMRd status. Although this observation does not explicitly rule out a role for ARID1A influence on CD8+ TIL infiltration in ENOC, given current knowledge regarding MMRd, it seems more likely that effects are dominated by the hypermutation phenotype. This large dataset with consistently applied biomarker assessment now provides a benchmark for the prevalence of ARIDIA loss-of-function mutations in endometriosis-associated ovarian cancers and brings clarity to the prognostic significance.
\end{abstract}

\title{
KEY WORDS:
}

Clear cell ovarian carcinoma, Endometrioid ovarian carcinoma, Endometriosis-associated ovarian carcinoma, ARID1A, DNA mismatch repair, CD8, Immunohistochemistry, Outcomes 
medRxiv preprint doi: https://doi.org/10.1101/2021.09.16.21262993; this version posted September 21, 2021. The copyright holder for this

\section{Introduction}

Adenine-thymine rich interactive domain 1A (ARID1A) is a key member of the mammalian Switch/Sucrose Non-Fermentable (mSWI/SNF) chromatin remodeling complex which enables nucleosome conformation to promote DNA accessibility in an ATP-dependent process [1]. ARIDIA encodes a protein which facilitates target-specific DNA binding. By binding to transcription activators or repressors, it regulates DNA transcription $[2,3]$ and thus regulates a wide variety of cell cycle, differentiation, and development processes [4]. Recent experiments have also suggested that ARID1A interacts with regulators of the genomic stability/DNA damage and replication machinery [5-7]. ARIDIA is the most frequently mutated subunit of the SWI/SNF complex detected in a broad spectrum of human cancers including gastrointestinal tract, lung, and breast malignancies [3,8,9]. Genome-wide sequencing analyses have identified ARIDIA inactivation across ovarian malignancies, generally restricted to endometriosis associated ovarian carcinoma (EAOC) - clear cell (CCOC) and endometrioid ovarian carcinomas (ENOC). Loss-of-function (LOF) mutations in ARIDIA have been reported in close to $50 \%$ of CCOC and $30 \%$ of ENOC [10-12]. In addition, genomic and functional studies have demonstrated that ARID1A inactivation promotes a malignant phenotype and is an early event in cancer pathogenesis; inactivation is broadly implicated in cancer progression, [13,14] yet it appears insufficient to drive transformation or tumor formation alone [10,15-20].

Somatic mutations in ARIDIA are dominantly loss-of-function nonsense or frameshift mutations (insertion/deletion) that result in loss of protein expression and corresponding immunoreactivity in immunohistochemistry-based assessment. Therefore, the use of immunohistochemistry (IHC) to determine aberrant ARID1A protein expression and expression patterns is widely accepted and proven to work as a surrogate marker for ARIDIA LOF mutations - as long as stringent methodology and appropriate antibody selection is 
medRxiv preprint doi: https://doi.org/10.1101/2021.09.16.21262993; this version posted September 21, 2021. The copyright holder for this

adhered to $[10,21]$. While a consensus on IHC usage now exists, there are contradictory reports on ARID1A loss of protein expression/mutation with respect to outcomes (Table 1). Some groups have observed ARID1A depletion to be associated with favourable prognosis in a study of ARIDIA mutation in the setting of impaired DNA (mismatch) repair mechanism in endometrial carcinomas. In contract, others suggest an adverse outcome relying on clinical prognostic features, and finally some studies fail to find associations in any way [22-26].

The correlation of ARIDIA mutational status with outcomes in different cancer types is varied. ARID1A inactivation correlates with poor outcome in breast, bladder, and bone malignancies $[9,27,28]$ while it has no apparent prognostic significance in esophageal adenocarcinoma [29]. In endometrial carcinoma ARIDIA LOF mutations are seen as favorable prognostic biomarker, though potentially confounded with impaired DNA mismatch repair (MMR) [30,31], and a target for development of new therapeutic interventions [32-34].

In ovarian carcinomas the prognostic significance of ARIDIA LOF mutation remains equivocal. Conflicting reports have implied positive, negative, and lack of any association with outcome and clinical features [25-29]. ARID1A deficiency has been linked to elevated tumor infiltrating lymphocytes (TIL) within specific histotypes, however sample sizes in these studies are relatively small [35-37]. Confirmation of such a finding may be important for clinical management as TIL are associated with improved outcomes in many solid tumors including ovarian carcinomas, though the strongest effects are observed in HGSOC. Beneficial CD8+ TIL effects are notable in ENOC, where ARID1A alterations are also prevalent, though they do not appear to be as strong as trends observed in HGSOC [38]. Likewise, prognostic CD8+ TIL effects in other histotypes have not been observed though small sample sizes have hindered efforts. Poor response to conventional treatment in advanced EAOC and emerging evidence of benefits of immunomodulatory therapies in 
medRxiv preprint doi: https://doi.org/10.1101/2021.09.16.21262993; this version posted September 21, 2021. The copyright holder for this

EAOC treatment suggests there may be considerable value in validating biomarker predictive of their activity $[39,40]$. As noted above, ARID1A alterations appear enriched in DNA mismatch repair deficient $(\mathrm{MMRd})$ endometrial carcinomas, a feature also common in ENOC, and generally associated with improved outcomes [22,30,41-43].

Herein, we leverage collective and consortia-based ovarian carcinoma tissue collections from the Ovarian Tumour Tissue Analysis Consortium, the Canadian Ovarian Experimental Unified Resource, local resources, and collaborations to investigate the prognostic and clinicopathological association of ARID1A loss-of-function alteration in ovarian carcinomas. We also re-visit CD8+ TIL infiltration and MMRd status, published previously $[38,43]$, now in the context of ARID1A LOF ovarian carcinoma.

\section{Materials and Methods}

Sample collection

A total of 5115 ovarian carcinoma cases of all histotypes were initially included with detailed examination on a subset of 1623 EAOC including 1078 ENOC and 545 CCOC. Participating studies included collections from the Ovarian Tumor Tissue Analysis (OTTA) consortium $(\mathrm{CCOC}=386, \mathrm{ENOC}=558$; and all non-EAOC cases $\mathrm{n}=2598)$, the Canadian Ovarian Experimental Unified Resource (COEUR) repository $($ ENOC=156), local Vancouver cohort $(\mathrm{VAN})(\mathrm{ENOC}=217, \mathrm{CCOC}=159)$ and from German collaborators (Tübingen, Essen, Heidelberg, Friedrichshafen; ENOC=147). The project was conducted in compliance with the Canadian Tri-Council Policy Statement on Ethical Conduct for Research Involving Humans (TCPS2, 2018); usage of specimen and associated clinical data was approved by local institutional research ethics boards (see also Table S1). Histotype review and confirmation on the OTTA and COEUR cohorts has been described previously, including both central and histotype-specific IHC [44]. All other samples were pathologist reviewed and subject to 
medRxiv preprint doi: https://doi.org/10.1101/2021.09.16.21262993; this version posted September 21, 2021. The copyright holder for this

confirmation using histotype specific IHC $[43,45]$. Detailed information regarding sample collections, tissue microarray (TMA) construction, pathological variables, and clinical data of participants in the OTTA, COEUR and VAN and German cohort have been described previously $[43,46,47]$.

\section{Immunohistochemistry and Scoring}

IHC was performed on TMA for ARIDA1 (details in Supplemental methods). A subset of cases from COEUR, VAN and Germany were stained for MMR proteins (MLH1, PMS2, MSH2, MSH6) (Figure S1). The immunohistochemical method and scoring has been provided in prior published studies $[43,48]$ (see also Supplemental methods). CD8+ TIL scores for OTTA samples were taken from Goode et al. [38] wherein staining and scoring was replicated in the same lab and pathologist (MK) for additional cohorts. Regarding the interpretation, ARID1A was assessed for nuclear staining in tumour epithelium (absent, present, subclonal) with retained stromal nuclear staining serving as an obligate internal control. During analysis ARID1A absence and subclonal scores were merged (unless otherwise noted in the text). Samples were considered MMRd if loss of staining in any of the four MMR markers was observed (with retained stromal staining serving as an obligate internal control [43]). CD8+ TIL infiltration was binned by counting and averaging the number of $\mathrm{CD} 8+$ cells in the tumor epithelium of TMA cores $(0=$ none, low $=1-2$, moderate $=3-19$, high $\geq 20[38])$.

\section{Statistical analysis}

Statistical analyses were conducted separately for ENOC and CCOC. Grade 1 was considered low and grades 2-4 as high grade. For stage-stratified analysis FIGO I and II were defined as low-stage and FIGO III and IV as high-stage. Welch's one-way or Chi Square tests were used to evaluate univariable association for continuous and categorical data, respectively. Clinical follow up was left truncated and, if exceeding 10 years, right censored as at December 31st of 
medRxiv preprint doi: https://doi.org/10.1101/2021.09.16.21262993; this version posted September 21, 2021. The copyright holder for this

the 10th year post diagnosis to minimize ascertainment bias and ensure non-informative censoring. The survival outcome measures, overall, disease-specific, and progression-free survival were assessed via Kaplan-Meier plotting and statistical significance was determined using a log-rank test. To calculate the multivariable effect of ARID1A LOF and other clinicopathological parameters on the survival outcome, Cox proportional hazards models were applied. In situations where more than $80 \%$ censoring occurred within a minimum of one variable, hazard estimates were generated using the Firth bias reducing correction. $P$ values of $<0.05$ were considered significant.

\section{Results}

\section{ARID1A loss is a feature of endometriosis-associated ovarian histotypes.}

A total of 5115 cases were examined by ARIDIA mutation surrogate IHC across all major histotypes (Table S2). Clinicopathological variables including age, stage, grade (ENOC only) and residual disease were factored into overall (OS), progression-free (PFS) and diseasespecific (DSS) survival. Our combined cohort is not population based and is deliberately enriched for ENOC specific sub-analysis discussed below: $2 \%$ of cases were classified as low (LGSOC), 51\% high-grade serous ovarian carcinoma (HGSOC), $21 \%$ as ENOC, $11 \%$ as clear cell ovarian carcinoma (CCOC), 5\% as mucinous ovarian carcinoma (MOC) and 10\% as other (including borderline tumors) (Table S2). Protein expression for ARID1A was detected in $\geq 94 \%$ of LGSOC, HGSOC, and MOC, while ARID1A loss was most prevalent in ENOC (25\%; including subclonality in 19 cases, or $2 \%$ of all) and CCOC (42\%; including subclonality in 7 cases, or $1 \%$ of all). ARID1A loss was significantly enriched in EAOC $(\mathrm{p}<0.001)$ (Figure 1A).

\section{Clinicopathological associations within EAOC cohorts.}


Our sample set appeared consistent with expected clinicopathological associations across stage, grade (considered for ENOC only), and residual disease in ENOC and CCOC in univariable analysis (Figure 1B-C; Table 2; Figure S2, S3). In multivariable survival analysis stage and grade were significantly associated with all outcome endpoints in ENOC (OS, DSS, and PFS: all p<0.05, Table 3A). Grade retained significance when the analysis was limited to low-stage (FIGO I/II) ENOC (OS, DSS, PFS all p<0.05, Table 3B). Presence of residual disease was associated with reduced DSS $(\mathrm{p}=0.026)$ and PFS $(\mathrm{p}=0.011)$ which again was consistent when examining PFS in only high-stage (FIGO III/IV) $(\mathrm{p}=0.002$, Table 3C). Across CCOC, in multivariable survival analysis stage and residual disease were significantly associated with outcome endpoints when examining all cases or somewhat when restricting to low-stage (stage all $\mathrm{p}<0.001$; residual disease all OS and PFS $\mathrm{p}<0.05$, low-stage OS $\mathrm{p}=0.034$, Table $3 \mathrm{~A}+\mathrm{B})$. Age was independently associated with all survival outcomes in CCOC regardless of looking at the full cohort $(\mathrm{p}<0.01$, Table $3 \mathrm{~A})$, restricting to high-stage $(\mathrm{p}<0.05)$ (Table 3C), or OS in low-stage $(\mathrm{p}=0.038$, Table 3B).

\section{Clinicopathological associations of ARID1A loss within EAOC cohorts.}

In univariable non-parametric analysis, no association between ARID1A loss and the clinicopathological variables stage, grade (ENOC), or residual disease was seen in ENOC or CCOC (Table S4A, S4B), and this was consistent with respect to grade and residual disease when considering low-stage and high-stage cases separately. In low-stage ENOC, FIGO I was less commonly associated with ARID1A loss than in FIGO II cases (24\% vs. 31\%, $\mathrm{p}=0.034$, data not shown) Amongst ENOC, ARID1A loss was significantly associated with a younger age of diagnosis, regardless of stage (mean age 55 vs. 57 respectively; $\mathrm{p}=0.012$, Table S4A). ARID1A loss was associated with younger age at diagnosis in high-stage CCOC cases (mean 52 vs. 58; $\mathrm{p}=0.001$, data not shown), but not low-stage CCOC. ARID1A loss status showed no significant associations with OS or PFS ( $p>0.05)$ in ENOC (Figure 1D-F). 
medRxiv preprint doi: https://doi.org/10.1101/2021.09.16.21262993; this version posted September 21, 2021. The copyright holder for this

A significant association was observed for DSS in ENOC in univariable analysis $(p=0.035)$.

Of note, the subset of cases with DSS reported ( $\mathrm{n}=936 / 1078 ; 87 \%$ of the cohort) showed a trend to lower stage and proportion of cases with optimal debulking compared to the complete case set analyzed for OS. In CCOC, we observed no association of OS, DSS, or PFS with ARID1A (p>0.1) (Figure 1G-I). No correlation between ARID1A loss and survival in either EAOC histotypes was observed in stage-based sub-analyses (Table S3). ARID1A loss was not an independent prognostic factor upon multivariable analysis for either ENOC or CCOC (Table 3).

\section{Association of ARID1A loss with CD8 TIL in CCOC and ENOC}

We re-examined published data for the OTTA cohort [38] and newly generated CD8 IHC data on all other cases performed with the same assays and interpretation. CD8+ TIL scores were available for 933 ENOCs and 480 CCOCs and amongst those $26 \%$ of ENOCs and $44 \%$ of CCOCs showed an ARID1A loss (Figure 1B-C). In ENOC the loss of ARID1A was significantly associated with the presence of CD8+ TIL $(\mathrm{p}=0.008)$. The proportion of tumors with ARID1A loss increased with increasing levels of CD8+ TIL amongst ENOC: from 22\% loss in CD8+ TIL negative to $37 \%$ loss in CD8+ TIL $\geq 20$ (Table 4A; $\mathrm{p}=0.008$ ). Notably, CD8+ TIL was also associated with MMR status amongst ENOC $(\mathrm{p}<0.001$; Table 4A; see also below). In CCOC we also observed a slight increase in the proportion of cases with ARID1A loss as CD8+ TIL increased; however, this association did not reach statistical significance (Table 4B). Similarly, while we did observe a significant trend of increasing CD8+ TIL with MMRd in CCOC, it should be noted that there were few observed cases with MMRd in CCOC (5\% overall). We did not observe any association between CD8+ TIL and grade (for ENOC) or stage in either histotype (Table 4).

Kaplan-Meier and univariable survival analysis failed to show any significant influence of CD8+ TIL on DSS and PFS in either ENOC or CCOC outcomes (Figure S4A, Table S5). 
medRxiv preprint doi: https://doi.org/10.1101/2021.09.16.21262993; this version posted September 21, 2021. The copyright holder for this

However, amongst ENOC, CD8+ TIL high $(\geq 3)$ patients showed a modest, yet significant, improvement in OS compared to patients with lower levels $(\leq 2)$ of CD8+ TIL $(p=0.002)$. No trend in OS was seen in CCOC. In stage stratified sub-analysis CD8+ TIL was associated with OS and PFS in low-stage ENOC $(\mathrm{p}<0.05)$ and with OS, DSS, and PFS in high-stage $\operatorname{CCOC}(\mathrm{p}<0.05$, data not shown).

\section{ARID1A loss correlation with DNA mismatch repair status in ENOC}

MMR status was available in 661 of 1078 ENOC cases. Absence of IHC staining in one or more of the evaluated MMR proteins (MLH1, MSH2, MSH6, PMS2) was seen in 87 cases and 36 exhibited both MMRd and ARID1A loss. 22\% of all ENOC-ARID1A loss cases had concurrent MMR deficiency resulting in a significant association between ARID1A and MMR status ( $\mathrm{p}<0.001$; Figure 1B, Table S6).

Evaluating the specific MMR protein patterns, an enrichment between ARID1A loss and MLH1 and PMS2 loss was observed, even when only considering low-stage ENOC ( $\mathrm{p}=0.013$ and $\mathrm{p}<0.001$, respectively, Table S6). This significant association is characterised by a 2.2 to 4-fold increased likelihood of detecting loss of MLH1 or PMS2 in combination with ARID1A loss compared to those that retained ARID1A staining. MMR status did not influence any measured outcome parameters (OS, DSS, PFS p>0.5, Table S7, Figure S5). Examination of ARIDIA genetic variants, where data was available from previous studies $[10,49,50]$, also showed ARIDIA indel mutation were more commonly the cause of LOF mutations in ARIDIA amongst MMRd ENOC compared to MMRp ENOC ( $\mathrm{p}=0.011$, Table S8).

Given the association of ARID1A loss with MMRd status we further examined this MMRd ENOC subset $(n=87)$. Within the MMRd subset ENOC cases affected by ARID1A loss tended to be younger than MMRd ENOC with retained ARID1A expression, though not statistically significant (mean 52 vs. 56 y/o, p=0.129, Table S9A). No age difference was 
medRxiv preprint doi: https://doi.org/10.1101/2021.09.16.21262993; this version posted September 21, 2021. The copyright holder for this

observed amongst MMR-proficient (MMRp) ENOC (mean 56 vs. 57 y/o; p=0.251, data not shown). There was no correlation with tumor grade or stage ( $>0.5$, Table S9A) albeit the sample size was small. As ARIDIA indel mutations were more prevalent in MMRd ENOC (Table S8) we also considered that, if MMRd was causative of ARIDIA mutations, one might expect a higher frequency of subclonal ARID1A alterations in this group. However, with only 19 cases showing subclonal ARID1A staining amongst ENOC our dataset was likely insufficient and only 3 were MMRd; no significant association was observed.

We also examined the relationship of clinicopathological features and survival within MMRd ENOC. Residual disease was of borderline significance for DSS ( $\mathrm{p}=0.041$, but not OS or PFS; Table S9B). Stage had a greater influence and was significant $(\mathrm{p} \leq 0.01)$ for OS, and PFS (Table S9B). We were not able to discern differences in outcome related to other variables (age, grade, ARID1A, or CD8+ TIL) within this comparably small subset of MMRd ENOC (Table S9B). In the larger subset of MMRp ENOC nearly all variables reflected trends seen with the full cohort and significant associations were observed for OS, DSS, and PFS across grade, stage, and residual disease. In MMRp ENOC age retained significance for DSS and PFS, and DSS only for CD8+ TIL status ( $\mathrm{p}<0.05$; Table S10).

\section{Discussion}

In the present study, the prognostic significance of ARID1A loss-of-function was evaluated in a cohort of 1623 endometriosis-associated ovarian carcinoma patients with clinicopathological variables, MMR status and CD8+ TIL included as additional biomarkers of interest. Our series appears to represent the largest data set reporting on prognostic significance of ARID1A in (endometriosis-associated) ovarian carcinomas to date and is important to clear confusion on clinicopathological and prognostic associations of ARID1A loss, as a surrogate for LOF mutations. 
medRxiv preprint doi: https://doi.org/10.1101/2021.09.16.21262993; this version posted September 21, 2021. The copyright holder for this

As expected, clinicopathological features such as stage, grade (only for ENOC), and residual disease were confirmed as prognostic factors in EAOC. Our results are consistent with published data on the frequency of ARID1A alterations but now provided a more accurate benchmark: CCOC (42\%) and ENOC (25\%) [10-12]. Differences in ARIDIA mutation frequencies relative to other reports may be due to smaller cohort sizes in other reports. Alternatively, because IHC reflects loss-of-function mutations, it is potentially unable to capture other non-synonymous somatic substitution mutations with unknown pathological effects and relevance. Nonetheless our data are in line with other emerging large-scale sequencing-based reports on CCOC (manuscript in prep [51]).

Our report confirms that ARID1A loss, as a surrogate for mutation status, has no impact on OS, or PFS in ENOC or CCOC. This is in contrast with other smaller scale studies suggesting either positive $[23,37,52]$ or negative prognostic relationship for ARID1A loss in EAOCs [53-55]. It is also in contrast to findings in other cancer types where ARID1A inactivation has been depicted as a predictor of poor prognosis [56,57]. At least some of these prior studies in other cancers are small or moderate in size, with higher potential for type 1 errors, thus suggesting that larger studies with cancer-type context may be warranted [58].

Previous reports have suggested ARID1A loss is more prevalent in younger CCOC [25]. We partially validated this finding in our larger cohort of CCOC; however, ARID1A loss was only associated with younger age amongst high-stage CCOC. We also found ARID1A loss was more prevalent in younger aged ENOC overall. However, the younger age at diagnosis amongst ENOC patients was confounded by MMR status; it is already known that MMRd status is associated with younger age at diagnosis [43]. Herein, acquisition of an ARIDIA loss-of-function mutation in the context of MMRd ENOC may be an effect modifier, and we observed that such cases retain an association with younger age at diagnosis compared to MMRd ENOC without ARID1A loss. ARID1A loss has been hypothesized to increase cell 
medRxiv preprint doi: https://doi.org/10.1101/2021.09.16.21262993; this version posted September 21, 2021. The copyright holder for this

proliferation and likewise restoration of wildtype ARID1A appears to be more proliferation rate-limiting $[59,60]$. One may speculate that MMRd/ARID1A loss lesions may grow more rapidly, yet remain restricted to an ovarian microenvironment [61], resulting in more prevalent symptoms and younger discovery. This hypothesis is clearly dependent on very specific features of differentiation and somatic molecular background. Context-specific functional studies will be needed to deconvolute ARID1A functions in these cases. Earlier ENOC onset is typical for Lynch syndrome carriers whose disease is characterized by dysfunction in MMR pathway and is readily detectable in gynecological malignancies [62]. The influence of Lynch carriers on the younger age of MMRd ENOC may not be the sole explanation for this group's younger age at diagnosis. Loss affecting MSH2, MSH6, or PMS2 (in the presence of intact MLH1) affected 49 out of 104 MMRd EAOC (39 ENOC, 10 CCOC) cases of probable Lynch syndrome. However, germline testing was not carried out in our cohort, and a recent analysis of germline MMR defects confirmed Lynch syndrome in 8/12 probable cases $(67 \%)[63,64]$, none amongst those with concurrent PMS2/MLH1 loss by IHC.

We report a strong association between ARID1A loss and MMR deficiency, consistent with prior studies, including those investigating endometrial and ovarian endometrioid carcinomas $[12,13,65-67]$. Likewise, our data suggests MMRd may precede, and be causative of indel type ARIDIA LOF mutations in MMRd ENOC. Despite this connection we did not observe an association between subclonal staining of ARID1A and MMRd, as might be expected. However, our TMA-based approach is not well suited to detect subclonal staining patterns and we lacked deep sequencing data on the MMRd subset of cases that would be definitive of subclonal ARIDIA alterations.

The association of ARID1A loss and CD8+ TIL infiltration in ENOC was also confounded by MMR status. We found that ARID1A loss in ENOC did correlate with increasing CD8+ 
medRxiv preprint doi: https://doi.org/10.1101/2021.09.16.21262993; this version posted September 21, 2021. The copyright holder for this

TIL density, and while TIL density was prognostic [38], ARID1A status was not. The association between MMRd and increasing CD8+ TIL density was also highly significant. As high neoantigen load generated by the hyper-mutation MMRd phenotype is well recognized to drive immune infiltration, this may be the more dominant driver for this observation [50]. Furthermore, MMRd is relative uncommon in CCOC with $5 \%$ in our cohort and $1.7 \%$ in a recent series [64].

Two recent studies suggested that ARID1A depleted ovarian tumors had increased CD8+ TIL infiltration [35,37]. It should be noted both studies' scoring parameters for CD8 or ARID1A were not presented, their ARID1A IHC did not use a validated antibody known to act as a surrogate of LOF mutations [21], and one of the study cohorts was a mix of CCOC and HGSOC [35]. Our standardized approach, and large-scale analysis, did not result in any significant relationship between ARID1A loss and CD8+ TIL infiltration amongst CCOC. In fact, high CD8+ TIL infiltration amongst CCOC was observed in only $12 \%$ of our cohort [38]. This is a striking difference to the proportion of ARID1A "low" and CD8 "high" which may have been as much as $74 \%$ in the Shen et al. report or the $20-30 \%$ CD8 "positive" reported for ARIDIA mutant/loss in the Kuroda report [35,37]. Both Shen et al. and Kuroda et al. suggest ARIDIA mutations are associated with higher tumor mutation burden in CCOC, with Shen et al. suggesting this is due to lost interactions with the MMR complex and subsequent phenotypic deficiency in MMR. Our current study did not examine tumor mutation burden, though prior work may support a slight increase with ARIDIA mutation [50]; however, the mutation signatures in CCOC are not consistent with a pattern that would be expected (i.e. COSMIC signatures 6, 15, 20 and/or 26) if ARIDIA loss leads to deficiencies in DNA mis-match repair or a hypermutation phenotype [50].

As endometriosis-associated ovarian cancers account for only $\sim 25 \%$ of ovarian carcinomas, studying these rarer ovarian histotypes can be particularly challenging. A strength of the 
medRxiv preprint doi: https://doi.org/10.1101/2021.09.16.21262993; this version posted September 21, 2021. The copyright holder for this

present study was the availability of a large number of EAOC cases $(n=1623)$ through local and collaborative/consortia-based collections that have undergone extensive review and immunohistochemical validation of histology. 545 CCOC and 1078 ENOC cases were stained for ARID1A LOF and sub-analyses of MMR and CD8+ TIL status were performed. We also applied centralized and uniform immunohistochemical assays with validated scoring parameters. In particular, we have benefitted from the sequence-based validation of ARID1A IHC as a mutation surrogate and a well-developed standard for characterization of MMR status $[10,21,49]$. Earlier study findings may have been affected by a lack of consensus on applied scoring systems and mixed usage of varying commercially available antibodies, as noted above.

We recognize that our study is limited by the use of TMA based resources with reduced ability to detect subclonal staining for our biomarkers of interest. In fact, varied expression patterns of ARID1A within a tumor might influence the prognosis in gastric cancer [68] and these subclonal patterns may result in clonal expansion and progressive tumor evolution [12]. We also recognize that CD8+ TIL infiltration was captured only in a semi-quantitative fashion, though given availability of historical data we felt it was justifiable to maintain the previous scoring system for comparability and our data appears to be in line with more quantitative reports [69-71]. CD8+ TIL infiltration is also a relatively limited picture of immune infiltration. While CD8+ TIL have shown to be prognostic in HGSOC it is entirely reasonable to assume other immune populations are more important to the establishment, and progression of EAOC. Such a hypothesis is consistent with the recent report of a (prognostic) subset of CCOC with a high-immune/inflammatory gene expression profile (so called "MesCC"), a profile that the authors point out is not driven by CD8+ TIL-specific signatures [36]. Additionally, we are aware that despite the large cohort size overall, subset analysis of MMRd ENOC is underpowered making conclusive statements difficult within this group. 
Further expansion of our cohort and collection of additional molecular data would be favourable, especially for ENOC where inclusion of POLE mutation status was not possible due to the nature of available samples (in TMA format only). Including POLE status would have enabled the entire cohort to be examined in the context of modern molecular subtypes of endometrioid carcinomas [43]. Likewise, such subtype classification structure has not been widely explored in $\mathrm{CCOC}$ and more rigorous molecular analysis including mutational biomarkers and/or epigenetic states may be highly valuable in future analyses of this cohort.

Finally, it should be noted that the lack of prognostic significance for ARID1A does not discount continued development of direct targeting, synthetic lethal strategies, and/or investigation into predictive value of ARID1A for immune-modulatory therapies [72-75]. As one of the most prevalent biomarkers in EAOCs it is a potentially high value biomarker with mechanisms of action that may be dependent on molecular context of the cancer (and subtype) in which alterations occur. Future, well-warranted, theragnostic development around ARID1A must take note of potential confounders and molecular context. 


\begin{abstract}
Abbreviations:
CCOC - clear cell ovarian carcinoma, COEUR - Canadian Ovarian Unified Experimental

Resource, EAOC - endometriosis-associated ovarian carcinoma, ENOC - endometrioid

ovarian carcinoma, HGSOC - high grade serous ovarian carcinoma, IHC -

immunohistochemistry, LOF - loss-of-function (expression), MMRd - mismatch repair

deficient, MSI - microsatellite instability, OS - overall survival, OTTA - ovarian tumor tissue analysis consortium, PFS - progression-free survival, TIL - tumor infiltrating lymphocytes,

TMA - tissue microarray
\end{abstract}

\title{
Acknowledgement:
}

We thank all the study participants who contributed to this study and all the researchers, clinicians, technical and administrative staff who have made this work possible. This research was funded in part by the Janet D. Cottrelle Foundation and the Canadian Institutes of Health Research (Early Career Investigator Grant to M.S. Anglesio). K. Heinze is funded through a research scholarship by the Deutsche Forschungsgesellschaft (HE 8699/1-1). A. Talhouk is funded through a Michael Smith Foundation for Health Research Scholar Award. M. Köbel received support through the Calgary Laboratory Services research support fund (RS19-612). We thank Shuhong Liu and Young Ou (Anatomical Pathology Research Laboratory) for performing immunohistochemistry. M.S. Anglesio is funded through a Michael Smith Foundation for Health Research Scholar Award and the Janet D. Cottrelle Foundation Scholars program managed by the BC Cancer Foundation. BC's Gynecological Cancer Research team (OVCARE) receives support through the BC Cancer Foundation and The VGH+UBC Hospital Foundation. This study uses resources provided by the Canadian Ovarian Cancer Research Consortium's COEUR biobank funded by the Terry Fox Research Institute and managed and supervised by the Centre hospitalier de l'Université de Montréal (CRCHUM). The Consortium acknowledges contributions to its COEUR biobank from Institutions across Canada (for a full list see http://www.tfri.ca/en/research/translational-research/coeur/coeur biobanks.aspx).

Ovarian tumor tissue analysis consortium studies were supported through independent mechanisms. The WMH study was supported by the Westmead Hospital Department of Gynaecological Oncology. The Gynaecological Oncology Biobank at Westmead, a member of the Australasian Biospecimen Network-Oncology group, was funded by the National 
Health and Medical Research Council Enabling Grants ID 310670 \& ID 628903 and the Cancer Institute NSW Grants ID 12/RIG/1-17 \& 15/RIG/1-16. The Westmead GynBiobank acknowledges financial support from the Sydney West Translational Cancer Research Centre. The Sydney West Translational Cancer Research Centre is funded by the Cancer Institute NSW. The BGS is funded by Breast Cancer Now and the Institute of Cancer Research (ICR). ICR acknowledges NHS funding to the NIHR Biomedical Research Centre. We thank the study staff, study participants, doctors, nurses, health care providers and health information sources who have contributed to the study. The SWE study, KS, CM, AL, and the GynCancer Biobank in Western Sweden is financed by Swedish Cancer foundation (KS), Swedish state under the agreement between the Swedish government and the county council, the ALFagreement (KS) and Assar Gabrielsson foundation (CM, AL). The DOV study is funded by National Health Institute grants ID R01-CA168758, R01-CA112523 and R01-CA087538. The GER study was supported by the German Federal Ministry of Education and Research, Programme of Clinical Biomedical Research (01 GB 9401) and the German Cancer Research Center (DKFZ), and thanks Sabine Behrens for competent technical assistance. The HAW study was funded by National Institute of Health and National Cancer Institute Grants ID N01-CN-25403/CN, N01-CN-67001/CN, P30-CA-71789/CA and R01-CA-58598/CA. The HOP study was supported by National Institute of Health and National Cancer Institute Grants ID K07-CA80668, R01CA095023, and R01 CA126841, as well as by US Army Medical Research and Materiel Command DAMD17-02-1-0669 and NIH/National Center for Research Resources/General Clinical Research Center grant MO1- RR000056. MW is funded by the European Research Council Advanced Grant (H2020 BRCA-ERC under Grant Agreement No. 742432). The University of Cambridge has received salary support for author PDPP from the NHS in the East of England through the Clinical Academic Reserve. The SEA study (SEARCH) was supported through grants from Cancer Research UK (C490/A10119 C490/A10124 C490/A16561) and the UK National Institute for Health Research Biomedical Research Centres at the University of Cambridge.

\section{Author contribution:}

MSA and MK designed the study, MSA, MK, SJR, NM, KH identified specimens for the study, MK, SL, EC, PK processed samples, and performed experiments. MK, SL, and TMN reviewed pathology and generated/reviewed IHC data, KH, AT, DSC and SCYL provided statistical design input, KH drafted the manuscript. All authors revised the manuscript and approved submission of the final version. 
All other author contributed through collection, curation and maintenance of respective consortia based, or local institution, collections of patient samples including recruitment and consenting of patients, clinical care, abstraction of clinical data, and updating of outcome and follow up data.

\section{Conflict of interest statement:}

AdB received honoraria for advisory boards and/or lecturing from Roche, GSK/Tesaro, Astra Zeneca, BIOCAD, Clovis, Zodiac, Seagen, Pfizer. PH received grants and personal fees from Astra Zeneca, Roche, Clovis, Immunogen, GSK; grant support by Boehringer Ingelheim, Medac, Genmab, and public funding agencies (EU, DFG, German Cancer Aid) as well as personal fees from Sotio, Stryker, Zai Lab, MSD. MJS is employed by IQVIA since February 2021. DGH is a co-founder and shareholder of Contextual Genomics Inc., a somatic mutation testing laboratory; the company's work and interests do not overlap with the subject of, or methodologies, used in this article. DGH is an Associate Editor of The Journal of Pathology. The other authors declare no conflict of interest. 


\section{Reference}

1. Reisman D, Glaros S, Thompson EA. The SWI/SNF complex and cancer. Oncogene 2009; 28: 1653-1668.

2. Nie Z, Xue Y, Yang D, et al. A specificity and targeting subunit of a human SWI/SNF family-related chromatin-remodeling complex. Mol Cell Biol 2000; 20: 8879-8888.

3. Mathur R, Alver BH, San Roman AK, et al. ARID1A loss impairs enhancer-mediated gene regulation and drives colon cancer in mice. Nat Genet 2017; 49: 296-302.

4. Nagl NG, Jr., Patsialou A, Haines DS, et al. The p270 (ARID1A/SMARCF1) subunit of mammalian SWI/SNF-related complexes is essential for normal cell cycle arrest. Cancer Res 2005; 65: 9236-9244.

5. Dykhuizen EC, Hargreaves DC, Miller EL, et al. BAF complexes facilitate decatenation of DNA by topoisomerase IIalpha. Nature 2013; 497: 624-627.

6. Peng G, Yim EK, Dai H, et al. BRIT1/MCPH1 links chromatin remodelling to DNA damage response. Nat Cell Biol 2009; 11: 865-872.

7. Tsai S, Fournier LA, Chang EY, et al. ARID1A regulates R-loop associated DNA replication stress. PLoS Genet 2021; 17: e1009238.

8. Zhang Y, Xu X, Zhang M, et al. ARID1A is downregulated in non-small cell lung cancer and regulates cell proliferation and apoptosis. Tumour Biol 2014; 35: 57015707.

9. Lin YF, Tseng IJ, Kuo CJ, et al. High-level expression of ARID1A predicts a favourable outcome in triple-negative breast cancer patients receiving paclitaxelbased chemotherapy. J Cell Mol Med 2018; 22: 2458-2468.

10. Wiegand KC, Shah SP, Al-Agha OM, et al. ARID1A mutations in endometriosisassociated ovarian carcinomas. N Engl J Med 2010; 363: 1532-1543.

11. Jones S, Li M, Parsons DW, et al. Somatic mutations in the chromatin remodeling gene ARID1A occur in several tumor types. Hum Mutat 2012; 33: 100-103.

12. Guan B, Mao TL, Panuganti PK, et al. Mutation and loss of expression of ARID1A in uterine low-grade endometrioid carcinoma. Am J Surg Pathol 2011; 35: 625-632.

13. Wang K, Kan J, Yuen ST, et al. Exome sequencing identifies frequent mutation of ARID1A in molecular subtypes of gastric cancer. Nat Genet 2011; 43: 1219-1223.

14. Mao TL, Ardighieri L, Ayhan A, et al. Loss of ARID1A expression correlates with stages of tumor progression in uterine endometrioid carcinoma. Am J Surg Pathol 2013; 37: 1342-1348.

15. Anglesio MS, Bashashati A, Wang YK, et al. Multifocal endometriotic lesions associated with cancer are clonal and carry a high mutation burden. J Pathol 2015; 236: 201-209.

16. Chene G, Ouellet V, Rahimi K, et al. The ARID1A pathway in ovarian clear cell and endometrioid carcinoma, contiguous endometriosis, and benign endometriosis. Int $J$ Gynaecol Obstet 2015; 130: 27-30.

17. Yamamoto S, Tsuda H, Takano M, et al. PIK3CA mutations and loss of ARID1A protein expression are early events in the development of cystic ovarian clear cell adenocarcinoma. Virchows Arch 2012; 460: 77-87.

18. Ayhan A, Mao TL, Seckin T, et al. Loss of ARID1A expression is an early molecular event in tumor progression from ovarian endometriotic cyst to clear cell and endometrioid carcinoma. Int J Gynecol Cancer 2012; 22: 1310-1315.

19. Lakshminarasimhan R, Andreu-Vieyra C, Lawrenson K, et al. Down-regulation of ARID1A is sufficient to initiate neoplastic transformation along with epigenetic reprogramming in non-tumorigenic endometriotic cells. Cancer Lett 2017; 401: 1119. 
20. Chandler RL, Damrauer JS, Raab JR, et al. Coexistent ARID1A-PIK3CA mutations promote ovarian clear-cell tumorigenesis through pro-tumorigenic inflammatory cytokine signalling. Nat Commun 2015; 6: 6118.

21. Khalique S, Naidoo K, Attygalle AD, et al. Optimised ARID1A immunohistochemistry is an accurate predictor of ARID1A mutational status in gynaecological cancers. J Pathol Clin Res 2018; 4: 154-166.

22. Allo G, Bernardini MQ, Wu RC, et al. ARID1A loss correlates with mismatch repair deficiency and intact p53 expression in high-grade endometrial carcinomas. Mod Pathol 2014; 27: 255-261.

23. Itamochi H, Oumi N, Oishi T, et al. Loss of ARID1A expression is associated with poor prognosis in patients with stage I/II clear cell carcinoma of the ovary. Int J Clin Oncol 2015; 20: 967-973.

24. Lowery WJ, Schildkraut JM, Akushevich L, et al. Loss of ARID1A-associated protein expression is a frequent event in clear cell and endometrioid ovarian cancers. Int J Gynecol Cancer 2012; 22: 9-14.

25. Huang HN, Lin MC, Huang WC, et al. Loss of ARID1A expression and its relationship with PI3K-Akt pathway alterations and ZNF217 amplification in ovarian clear cell carcinoma. Mod Pathol 2014; 27: 983-990.

26. Ye S, Yang J, You Y, et al. Clinicopathologic Significance of HNF-1beta, AIRD1A, and PIK3CA Expression in Ovarian Clear Cell Carcinoma: A Tissue Microarray Study of 130 Cases. Medicine (Baltimore) 2016; 95: e3003.

27. Garczyk S, Schneider U, Lurje I, et al. ARID1A-deficiency in urothelial bladder cancer: No predictive biomarker for EZH2-inhibitor treatment response? PLoS One 2018; 13: e0202965.

28. Xu N, Wang L, Sun P, et al. Low Arid1a Expression Correlates with Poor Prognosis and Promotes Cell Proliferation and Metastasis in Osteosarcoma. Pathol Oncol Res 2019; 25: 875-881.

29. Drage MG, Tippayawong M, Agoston AT, et al. Morphological Features and Prognostic Significance of ARID1A-Deficient Esophageal Adenocarcinomas. Arch Pathol Lab Med 2017; 141: 970-977.

30. Bosse T, Nout RA, McAlpine JN, et al. Molecular Classification of Grade 3 Endometrioid Endometrial Cancers Identifies Distinct Prognostic Subgroups. Am J Surg Pathol 2018; 42: 561-568.

31. Tangjitgamol S, Kittisiam T, Tanvanich S. Prevalence and prognostic role of mismatch repair gene defect in endometrial cancer patients. Tumour Biol 2017; 39: 1010428317725834.

32. Toumpeki C, Liberis A, Tsirkas I, et al. The Role of ARID1A in Endometrial Cancer and the Molecular Pathways Associated With Pathogenesis and Cancer Progression. In Vivo 2019; 33: 659-667.

33. Takeda T, Banno K, Okawa R, et al. ARID1A gene mutation in ovarian and endometrial cancers (Review). Oncol Rep 2016; 35: 607-613.

34. Raffone A, Travaglino A, Saccone G, et al. Diagnostic and prognostic value of ARID1A in endometrial hyperplasia: a novel marker of occult cancer. APMIS 2019; 127: 597-606.

35. Shen J, Ju Z, Zhao W, et al. ARID1A deficiency promotes mutability and potentiates therapeutic antitumor immunity unleashed by immune checkpoint blockade. Nat Med 2018; 24: 556-562.

36. Tan TZ, Ye J, Yee CV, et al. Analysis of gene expression signatures identifies prognostic and functionally distinct ovarian clear cell carcinoma subtypes. EBioMedicine 2019; 50: 203-210. 
37. Kuroda Y, Chiyoda T, Kawaida M, et al. ARID1A mutation/ARID1A loss is associated with a high immunogenic profile in clear cell ovarian cancer. Gynecol Oncol 2021.

38. Ovarian Tumor Tissue Analysis C, Goode EL, Block MS, et al. Dose-Response Association of CD8+ Tumor-Infiltrating Lymphocytes and Survival Time in HighGrade Serous Ovarian Cancer. JAMA Oncol 2017; 3: e173290.

39. Matulonis UA, Shapira-Frommer R, Santin AD, et al. Antitumor activity and safety of pembrolizumab in patients with advanced recurrent ovarian cancer: results from the phase II KEYNOTE-100 study. Ann Oncol 2019; 30: 1080-1087.

40. Kawabata A, Yanaihara N, Nagata C, et al. Prognostic impact of interleukin-6 expression in stage I ovarian clear cell carcinoma. Gynecol Oncol 2017; 146: 609614.

41. Yamashita H, Nakayama K, Ishikawa M, et al. Relationship between Microsatellite Instability, Immune Cells Infiltration, and Expression of Immune Checkpoint Molecules in Ovarian Carcinoma: Immunotherapeutic Strategies for the Future. Int J Mol Sci 2019; 20.

42. Xiao X, Dong D, He W, et al. Mismatch repair deficiency is associated with MSI phenotype, increased tumor-infiltrating lymphocytes and PD-L1 expression in immune cells in ovarian cancer. Gynecol Oncol 2018; 149: 146-154.

43. Kramer P, Talhouk A, Brett MA, et al. Endometrial Cancer Molecular Risk Stratification is Equally Prognostic for Endometrioid Ovarian Carcinoma. Clin Cancer Res 2020; 26: 5400-5410.

44. Kobel M, Rahimi K, Rambau PF, et al. An Immunohistochemical Algorithm for Ovarian Carcinoma Typing. Int J Gynecol Pathol 2016; 35: 430-441.

45. Kalloger SE, Kobel M, Leung S, et al. Calculator for ovarian carcinoma subtype prediction. Mod Pathol 2011; 24: 512-521.

46. Sieh W, Kobel M, Longacre TA, et al. Hormone-receptor expression and ovarian cancer survival: an Ovarian Tumor Tissue Analysis consortium study. Lancet Oncol 2013; 14: 853-862.

47. Le Page C, Rahimi K, Kobel M, et al. Characteristics and outcome of the COEUR Canadian validation cohort for ovarian cancer biomarkers. BMC Cancer 2018; 18: 347.

48. Nelson GS, Pink A, Lee S, et al. MMR deficiency is common in high-grade endometrioid carcinomas and is associated with an unfavorable outcome. Gynecol Oncol 2013; 131: 309-314.

49. McConechy MK, Talhouk A, Li-Chang HH, et al. Detection of DNA mismatch repair (MMR) deficiencies by immunohistochemistry can effectively diagnose the microsatellite instability (MSI) phenotype in endometrial carcinomas. Gynecol Oncol 2015; 137: 306-310.

50. Wang YK, Bashashati A, Anglesio MS, et al. Genomic consequences of aberrant DNA repair mechanisms stratify ovarian cancer histotypes. Nat Genet 2017; 49: 856865.

51. Bolton KL, Chan D, Corona de la Fuente R, et al. Genomic subclasses of ovarian clear cell carcinoma and their impact on disease behavior and outcomes. Manuscript in preparation (unpublished) 2021.

52. Katagiri A, Nakayama K, Rahman MT, et al. Loss of ARID1A expression is related to shorter progression-free survival and chemoresistance in ovarian clear cell carcinoma. Mod Pathol 2012; 25: 282-288.

53. Yokoi A, Matsumoto T, Watanabe G, et al. Immunophenotypic profile as a predictor of prognosis in advanced ovarian carcinoma. Hum Pathol 2019; 85: 210-220. 
54. Heckl M, Schmoeckel E, Hertlein L, et al. The ARID1A, p53 and ss-Catenin statuses are strong prognosticators in clear cell and endometrioid carcinoma of the ovary and the endometrium. PLoS One 2018; 13: e0192881.

55. Zhai Y, Kuick R, Tipton C, et al. Arid1a inactivation in an Apc- and Pten-defective mouse ovarian cancer model enhances epithelial differentiation and prolongs survival. J Pathol 2016; 238: 21-30.

56. Yang L, Wei S, Zhao R, et al. Loss of ARID1A expression predicts poor survival prognosis in gastric cancer: a systematic meta-analysis from 14 studies. Sci Rep 2016; 6: 28919.

57. Hung YP, Redig A, Hornick JL, et al. ARID1A mutations and expression loss in nonsmall cell lung carcinomas: clinicopathologic and molecular analysis. Mod Pathol 2020; 33: 2256-2268.

58. Ioannidis JP. Why most published research findings are false. PLoS Med 2005; 2: e124.

59. Yang Y, Wang X, Yang J, et al. Loss of ARID1A promotes proliferation, migration and invasion via the Akt signaling pathway in NPC. Cancer Manag Res 2019; 11: 4931-4946.

60. Guan B, Wang TL, Shih Ie M. ARID1A, a factor that promotes formation of $\mathrm{SWI} / \mathrm{SNF}-$ mediated chromatin remodeling, is a tumor suppressor in gynecologic cancers. Cancer Res 2011; 71: 6718-6727.

61. Anglesio MS, Wang YK, Maassen M, et al. Synchronous Endometrial and Ovarian Carcinomas: Evidence of Clonality. J Natl Cancer Inst 2016; 108: djv428.

62. Mojtahed A, Schrijver I, Ford JM, et al. A two-antibody mismatch repair protein immunohistochemistry screening approach for colorectal carcinomas, skin sebaceous tumors, and gynecologic tract carcinomas. Mod Pathol 2011; 24: 1004-1014.

63. Hodan R, Kingham K, Cotter K, et al. Prevalence of Lynch syndrome in women with mismatch repair-deficient ovarian cancer. Cancer Med 2021; 10: 1012-1017.

64. Rodriguez M, al e. Accurate distinction of ovarian clear cell from endometrioid carcinoma requires integration of phenotype, immunohistochemical predictions and genotype: implications for Lynch syndrome screening Am J Surg Pathol 2021; accepted - in press.

65. Wiegand KC, Lee AF, Al-Agha OM, et al. Loss of BAF250a (ARID1A) is frequent in high-grade endometrial carcinomas. J Pathol 2011; 224: 328-333.

66. Kim KJ, Jung HY, Oh MH, et al. Loss of ARID1A Expression in Gastric Cancer: Correlation with Mismatch Repair Deficiency and Clinicopathologic Features. $J$ Gastric Cancer 2015; 15: 201-208.

67. Han N, Kim MA, Lee HS, et al. Loss of ARID1A Expression is Related to Gastric Cancer Progression, Epstein-Barr Virus Infection, and Mismatch Repair Deficiency. Appl Immunohistochem Mol Morphol 2016; 24: 320-325.

68. Kim YB, Ham IH, Hur H, et al. Various ARID1A expression patterns and their clinical significance in gastric cancers. Hum Pathol 2016; 49: 61-70.

69. Webb JR, Milne K, Kroeger DR, et al. PD-L1 expression is associated with tumorinfiltrating $\mathrm{T}$ cells and favorable prognosis in high-grade serous ovarian cancer. Gynecol Oncol 2016; 141: 293-302.

70. Webb JR, Milne K, Nelson BH. PD-1 and CD103 Are Widely Coexpressed on Prognostically Favorable Intraepithelial CD8 T Cells in Human Ovarian Cancer. Cancer Immunol Res 2015; 3: 926-935.

71. Webb JR, Milne K, Nelson BH. Location, location, location: CD103 demarcates intraepithelial, prognostically favorable CD8(+) tumor-infiltrating lymphocytes in ovarian cancer. Oncoimmunology 2014; 3: e27668. 
72. Lin $\mathrm{CH}, \mathrm{Vu} \mathrm{JP}$, Yang CY, et al. Glutamate-cysteine ligase catalytic subunit as a therapeutic target in acute myeloid leukemia and solid tumors. Am J Cancer Res 2021; 11: 2911-2927.

73. Lin YC, Wen KC, Sung PL, et al. Complete remission of heavily treated ovarian clear cell carcinoma with ARID1A mutations after pembrolizumab and bevacizumab combination therapy: a case report. J Ovarian Res 2020; 13: 143.

74. Ogiwara H, Takahashi K, Sasaki M, et al. Targeting the Vulnerability of Glutathione Metabolism in ARID1A-Deficient Cancers. Cancer Cell 2019; 35: 177-190 e178.

75. Takahashi K, Takenaka M, Okamoto A, et al. Treatment Strategies for ARID1ADeficient Ovarian Clear Cell Carcinoma. Cancers (Basel) 2021; 13.

76. Yano M, Katoh T, Miyazawa M, et al. Clinicopathological correlation of ARID1A status with HDAC6 and its related factors in ovarian clear cell carcinoma. Sci Rep 2019; 9: 2397.

77. Sato E, Nakayama K, Razia S, et al. ARID1B as a Potential Therapeutic Target for ARID1A-Mutant Ovarian Clear Cell Carcinoma. Int J Mol Sci 2018; 19.

78. Yokoyama Y, Matsushita Y, Shigeto T, et al. Decreased ARID1A expression is correlated with chemoresistance in epithelial ovarian cancer. J Gynecol Oncol 2014; 25: 58-63.

79. Luo Q, Wu X, Zhang Y, et al. ARID1A ablation leads to multiple drug resistance in ovarian cancer via transcriptional activation of MRP2. Cancer Lett 2018; 427: 9-17.

80. Suryo Rahmanto Y, Jung JG, Wu RC, et al. Inactivating ARID1A Tumor Suppressor Enhances TERT Transcription and Maintains Telomere Length in Cancer Cells. J Biol Chem 2016; 291: 9690-9699.

81. Maeda D, Mao TL, Fukayama M, et al. Clinicopathological significance of loss of ARID1 A immunoreactivity in ovarian clear cell carcinoma. Int J Mol Sci 2010; 11: 5120-5128.

82. Choi JY, Han HH, Kim YT, et al. Ovarian Clear Cell Carcinoma Sub-Typing by ARID1A Expression. Yonsei Med J 2017; 58: 59-66.

83. Kato M, Takano M, Miyamoto M, et al. Effect of ARID1A/BAF250a expression on carcinogenesis and clinicopathological factors in pure-type clear cell adenocarcinoma of the ovary. Mol Clin Oncol 2016; 5: 395-401. 
medRxiv preprint doi: https://doi.org/10.1101/2021.09.16.21262993; this version posted September 21, 2021. The copyright holder for this preprint (which was not certified by peer review) is the author/funder, who has granted medRxiv a license to display the preprint in perpetuity.

It is made available under a CC-BY-ND 4.0 International license.

Significance of ARID1A Status in EAOC

\section{Figure Legend}

Figure 1 Results from ARID1A classification in ovarian carcinomas. A Frequency of ARID1A loss detected in major ovarian carcinoma histological subtypes; 'other' contain cases of mixed cell, borderline and other specified epithelial ovarian tumors, B,C Oncoplot outlining full ENOC (B) and CCOC (C) cohort of cases (in columns) along with ARID1A, MMR and CD8+ status and clinicopathologic features, D-F Kaplan-Meier survival curves depicting OS ( $\mathrm{n}=1044)$, DSS $(\mathrm{n}=936)$ and PFS ( $\mathrm{n}=575)$ with absent vs. present ARID1A status in ENOC, G-I Kaplan-Meier survival curves depicting OS ( $\mathrm{n}=538)$, DSS $(\mathrm{n}=437)$ and PFS ( $\mathrm{n}=322)$ with absent vs. present ARID1A status in CCOC. 
medRxiv preprint doi: https://doi.org/10.1101/2021.09.16.21262993; this version posted September 21, 2021. The copyright holder for this preprint (which was not certified by peer review) is the author/funder, who has granted medRxiv a license to display the preprint in perpetuity.

It is made available under a CC-BY-ND 4.0 International license .

Significance of ARID1A Status in EAOC

\section{Table Legends}

Table 1 Contradictory effects of ARID1A alterations reported in ovarian carcinoma literature.

Table 2 Univariable Survival in EAOC. Summary of p-Values obtained during univariable survival analysis in ENOC and CCOC on clinicopathological and molecular parameters. Corresponding Kaplan-Meier curves are indicated and can be found in figure 1 and supplementary figures 2 and 3.

Table 3 Multivariable Survival in EAOC. A Multivariable survival model statistics when considering clinicopathological parameters and ARID1A for OS, DSS and PFS in the full ENOC and CCOC cohorts, $(\mathbf{B}-\mathbf{C})$ Multivariable survival model statistics in only low- (B) and only high-staged (C) ENOC and CCOC cohorts respectively.

Table 4 Influence of CD8+ in EAOC. Univariable association between CD8+ status and clinicopathological parameter and ARID1A status in ENOC $(\mathbf{A}, \mathrm{n}=933)$ and CCOC $(\mathbf{B}$, $n=480$ ). 
medRxiv preprint doi: https://doi.org/10.1101/2021.09.16.21262993; this version posted September 21, 2021. The copyright holder for this preprint (which was not certified by peer review) is the author/funder, who has granted medRxiv a license to display the preprint in perpetuity.

It is made available under a CC-BY-ND 4.0 International license .

Significance of ARID1A Status in EAOC

\section{Table 1}

\section{ARID1A mutation is associated with tumor promoting properties}

ARID1A mut correlates with poor prognosis, lower survival, high degree of $[23,25,26,35,52,76-80]$ mutability, chemotherapy resistance and early reoccurrence, progression, earlier disease onset

\section{ARID1A mutation has no effect}

ARID1A mut shows no survival difference, no difference in stages, no $[17,24,40,81-83]$ correlation to chemo sensitivity

\section{ARID1A mutation is associated with tumor suppressive properties ARID1A mut enhances patient survival, differentiation of epithelia, lack of [53-55] mut results in unfavorable outcome}


medRxiv preprint doi: https://doi.org/10.1101/2021.09.16.21262993; this version posted September 21, 2021. The copyright holder for this preprint (which was not certified by peer review) is the author/funder, who has granted medRxiv a license to display the preprint in perpetuity.

It is made available under a CC-BY-ND 4.0 International license .

Significance of ARID1A Status in EAOC

Table 2

\begin{tabular}{lllll}
\hline ENOC & OS & DSS & PFS & cf. (log-rank) \\
\hline age & $\mathbf{0 . 0 0 1}$ & $<\mathbf{0 . 0 0 1}$ & $<\mathbf{0 . 0 0 1}$ & \\
ARID1A & 0.892 & 0.135 & 0.525 & Fig.1 D-F \\
Grade & $<\mathbf{0 . 0 0 1}$ & $<\mathbf{0 . 0 0 1}$ & $<\mathbf{0 . 0 0 1}$ & Fig.S2 A, E, I \\
Stage & $<\mathbf{0 . 0 0 1}$ & $\mathbf{< 0 . 0 0 1}$ & $\mathbf{< 0 . 0 0 1}$ & Fig.S2 B, F, J \\
Residual disease & $<\mathbf{0 . 0 0 1}$ & $<\mathbf{0 . 0 0 1}$ & $<\mathbf{0 . 0 0 1}$ & Fig.S2 D, H, K \\
MMR status & 0.237 & 0.974 & 0.965 & Fig. S4 A-C \\
CD8+ status & $\mathbf{0 . 0 3 4}$ & 0.198 & 0.086 & Fig.S3 A-C \\
\hline CCOC & & & & \\
\hline age & $<\mathbf{0 . 0 0 1}$ & $<\mathbf{0 . 0 0 1}$ & $<\mathbf{0 . 0 0 1}$ & Fig.1G-I \\
ARID1A & 0.297 & 0.316 & 0.392 & Fig.S3 A, D, G \\
Stage & $<\mathbf{0 . 0 0 1}$ & $<\mathbf{0 . 0 0 1}$ & $\mathbf{< 0 . 0 0 1}$ & Fig.S3 C, F, I \\
Residual disease & $<\mathbf{0 . 0 0 1}$ & $\mathbf{0 . 0 0 1}$ & $<\mathbf{0 . 0 0 1}$ & \\
MMR status & 0.868 & 0.505 & 0.459 & 0.324 \\
CD8+ status & 0.377 & 0.522 & Fig.S3 D-F \\
\hline
\end{tabular}


medRxiv preprint doi: https://doi.org/10.1101/2021.09.16.21262993; this version posted September 21, 2021. The copyright holder for this preprint (which was not certified by peer review) is the author/funder, who has granted medRxiv a license to display the preprint in perpetuity.

Table 3

\begin{tabular}{|c|c|c|c|c|c|c|c|}
\hline & & OS & & DSS & & PFS & \\
\hline & & $\begin{array}{l}\text { HR } \\
(95 \% \mathrm{CI})\end{array}$ & $\begin{array}{l}\text { LRT } \\
\text { PValue }\end{array}$ & $\begin{array}{l}\text { HR } \\
(95 \% \mathrm{CI})\end{array}$ & $\begin{array}{l}\text { LRT } \\
\text { PValue }\end{array}$ & $\begin{array}{l}\text { HR } \\
(95 \% \mathrm{CI})\end{array}$ & $\begin{array}{l}\text { LRT } \\
\text { PValue }\end{array}$ \\
\hline ENOC & \# eventsín & $78 / 368$ & & $37 / 334$ & & $76 / 360$ & \\
\hline Age & & 1.05 & 0.299 & 1.02 & 0.835 & 1.25 & $<0.001$ \\
\hline \multirow[t]{3}{*}{ Stage } & Ш & 1.53 & & 1.34 & & 2.84 & \\
\hline & III & 3.71 & $<0.001$ & 3.17 & 0.017 & 4.14 & $<0.001$ \\
\hline & IV & 8.8 & & 8.59 & & 12.78 & \\
\hline Grade & high & 2.14 & 0.003 & 4.05 & $<0.001$ & 2.41 & $<0.001$ \\
\hline residual & optimal & 0.56 & 0.056 & 0.38 & 0.026 & 0.47 & 0.011 \\
\hline ARID1A & present & 1.03 & 0.929 & 1.04 & 0.931 & 1.13 & 0.669 \\
\hline $\mathrm{CCOC}$ & theventsín & $106 / 211$ & & $40 / 152$ & & $96 / 184$ & \\
\hline Age & & 1.15 & 0.001 & 1.22 & 0.006 & 1.52 & $<0.001$ \\
\hline \multirow[t]{3}{*}{ Stage } & II & 1.48 & & 1.06 & & 1.9 & \\
\hline & III & 4.88 & $<0.001$ & 6.19 & $<0.001$ & 7.5 & $<0.001$ \\
\hline & IV & 9.56 & & 13.87 & & 26.93 & \\
\hline residual & optimal & 0.55 & 0.030 & 0.7 & 0.444 & 0.43 & 0.005 \\
\hline ARID 1 A & present & 0.75 & 0.185 & 0.6 & 0.162 & 0.94 & 0.783 \\
\hline
\end{tabular}

B Low Stages HAOC (FIGO I+ II)

\begin{tabular}{llcccccc}
\hline LowENOC & Hevents/n & $45 / 302$ & & $19 / 282$ & & $42 / 296$ & \\
Age & & 1.04 & 0.528 & 0.98 & 0.859 & 1.28 & 0.001 \\
Stage & II & 1.58 & 0.190 & 1.22 & 0.720 & 2.96 & $\mathbf{0 . 0 0 2}$ \\
Grade & high & 2.29 & $\mathbf{0 . 0 1 2}$ & 3.41 & $\mathbf{0 . 0 1 3}$ & 2.19 & $\mathbf{0 . 0 1 6}$ \\
residual & optimal & 0.69 & 0.496 & 0.28 & 0.085 & 0.68 & 0.465 \\
ARID1A & present & 1.12 & 0.763 & 0.94 & 0.917 & 1.07 & 0.842 \\
\hline lowCCOC & Hevents/n & $53 / 148$ & & $18 / 118$ & & $44 / 139$ & \\
Age & & 1.12 & $\mathbf{0 . 0 3 8}$ & 1.16 & 0.115 & 1.61 & $<0.001$ \\
Stage & II & 1.34 & 0.314 & 1.17 & 0.762 & 1.79 & 0.080 \\
residual & optimal & 0.36 & $\mathbf{0 . 0 3 4}$ & $7.7 \mathrm{e}+07$ & 0.161 & 0.35 & 0.069 \\
ARID1A & present & 0.84 & 0.566 & 0.69 & 0.457 & 0.77 & 0.424 \\
\hline
\end{tabular}

C High Stage EAOC (FIGO III + IV)

\begin{tabular}{|c|c|c|c|c|c|c|c|}
\hline highENOC & h events/n & $33 / 66$ & & $18 / 52$ & & $34 / 64$ & \\
\hline Age & & 1.06 & 0.500 & 1.03 & 0.809 & 1.31 & 0.011 \\
\hline Stage & IV & 2.18 & 0.211 & 1.32 & 0.751 & 1.49 & 0.596 \\
\hline Grade & high & 1.59 & 0.280 & 4.77 & 0.041 & 2.54 & 0.047 \\
\hline residual & optimal & 0.47 & 0.085 & 0.38 & 0.133 & 0.24 & 0.002 \\
\hline ARID1A & present & 0.87 & 0.819 & 1.31 & 0.782 & 0.83 & 0.783 \\
\hline highCCOC & H events/n & $53 / 63$ & & $22 / 34$ & & $53 / 59$ & \\
\hline Age & & 1.31 & 0.002 & 1.55 & 0.002 & 1.46 & 0.022 \\
\hline Stage & IV & 2.14 & 0.270 & 3.52 & 0.244 & $4.7+\mathrm{e} 09$ & 0.006 \\
\hline residual & optimal & 0.69 & 0.267 & 0.43 & 0.196 & 0.32 & 0.010 \\
\hline ARIDIA & present & 0.66 & 0.266 & 0.86 & 0.802 & 1.37 & 0.504 \\
\hline
\end{tabular}


medRxiv preprint doi: https://doi.org/10.1101/2021.09.16.21262993; this version posted September 21, 2021. The copyright holder for this preprint (which was not certified by peer review) is the author/funder, who has granted medRxiv a license to display the preprint in perpetuity.

It is made available under a CC-BY-ND 4.0 International license.

Significance of ARID1A Status in EAOC

Table 4

\begin{tabular}{|c|c|c|c|c|c|c|c|}
\hline Variable & Levels & none & low & moderate & high & Total & PValue \\
\hline Total & $\mathrm{N}(\%)$ & $264(24 \%)$ & $189(18 \%)$ & $351(33 \%)$ & $129(12 \%)$ & $1078(100 \%)$ & \\
\hline \multirow[t]{2}{*}{ ARID1A } & absent/subclonal & $57(22 \%)$ & $48(25 \%)$ & $85(24 \%)$ & $48(37 \%)$ & $238(26 \%)$ & 0.008 \\
\hline & present & $207(78 \%)$ & $141(75 \%)$ & $266(76 \%)$ & $81(63 \%)$ & $695(74 \%)$ & \\
\hline \multirow[t]{3}{*}{ MMR } & MMRp & $147(93 \%)$ & $110(85 \%)$ & $233(90 \%)$ & $62(69 \%)$ & $552(87 \%)$ & $<0.001$ \\
\hline & MMRd & $11(7 \%)$ & $19(15 \%)$ & $27(10 \%)$ & $28(31 \%)$ & $85(13 \%)$ & \\
\hline & Missing & 106 & 60 & 91 & 39 & 296 & \\
\hline \multirow[t]{3}{*}{ Grade } & low grade & $142(59 \%)$ & $95(56 \%)$ & $201(60 \%)$ & $66(57 \%)$ & $504(59 \%)$ & 0.828 \\
\hline & high grade & $98(41 \%)$ & $75(44 \%)$ & $134(40 \%)$ & $49(43 \%)$ & $356(41 \%)$ & \\
\hline & Missing & 24 & 19 & 16 & 14 & 73 & \\
\hline \multirow[t]{5}{*}{ Stage } & I & $118(54 \%)$ & $98(59 \%)$ & $179(58 \%)$ & $65(59 \%)$ & $460(57 \%)$ & 0.643 \\
\hline & II & $60(27 \%)$ & $40(24 \%)$ & $90(29 \%)$ & $30(27 \%)$ & $220(27 \%)$ & \\
\hline & III & $38(17 \%)$ & $23(14 \%)$ & $32(10 \%)$ & $13(12 \%)$ & $106(13 \%)$ & \\
\hline & IV & $4(2 \%)$ & $4(2 \%)$ & $6(2 \%)$ & $3(3 \%)$ & $17(2 \%)$ & \\
\hline & Missing & 44 & 24 & 44 & 18 & 130 & \\
\hline
\end{tabular}

\begin{tabular}{cccccccc}
\hline Variable & Levels & none & low & moderate & high & Total & PValue \\
\hline Total & N (\%) & $243(45 \%)$ & $108(20 \%)$ & $66(12 \%)$ & $63(12 \%)$ & $545(100 \%)$ & \\
ARID1 A & absent/subclonal & $103(42 \%)$ & $45(42 \%)$ & $31(47 \%)$ & $30(48 \%)$ & $209(44 \%)$ & 0.795 \\
& present & $140(58 \%)$ & $63(58 \%)$ & $35(53 \%)$ & $33(52 \%)$ & $271(56 \%)$ & \\
MMR & MMRp & $136(99 \%)$ & $78(98 \%)$ & $34(92 \%)$ & $32(80 \%)$ & $280(95 \%)$ & $<0.001$ \\
& MMRd & $2(1 \%)$ & $2(2 \%)$ & $3(8 \%)$ & $8(20 \%)$ & $15(5 \%)$ & \\
& Missing & 105 & 28 & 29 & 23 & 185 & 0.822 \\
Stage & I & $109(53 \%)$ & $46(47 \%)$ & $23(43 \%)$ & $24(43 \%)$ & $202(49 \%)$ & 0.20 \\
& II & $56(27 \%)$ & $26(27 \%)$ & $17(31 \%)$ & $20(36 \%)$ & $119(29 \%)$ & \\
& III & $39(19 \%)$ & $25(26 \%)$ & $13(24 \%)$ & $11(20 \%)$ & $88(21 \%)$ & \\
& IV & $2(1 \%)$ & $1(1 \%)$ & $1(2 \%)$ & $1(2 \%)$ & $5(1 \%)$ & 66 \\
\hline
\end{tabular}


medRxiv preprint doi: https://doi.org/10.1101/2021.09.16.21262993; this version posted September 21, 2021. The copyright holder for this preprint (which was not certified by peer review) is the author/funder, who has granted medRxiv a license to display the preprint in perpetuity. It is made available under a CC-BY-ND 4.0 International license .

Significance of ARID1A Status in EAOC

\section{List of supplementary files}

Supplementary methods.docx

Includes additional detail on immunohistochemistry methods, antibodies and scoring parameters.

Table_S1-Study-Cohort.xlsx

Includes details of the cohorts and contributing consortia-based studies.

Supplementary tables.pdf

Includes Tables S2-S10.

Supplementary figures.pdf

Includes Figures S1-S5 
medRxiv preprint doi: https://doi.org/10.1101/2021.09.16.21262993; this version posted September 21, 2021. The copyright holder for this preprint (which was not certified by peer review) is the author/funder, who has granted medRxiv a license to display the preprint in perpetuity.

It is made available under a CC-BY-ND 4.0 International license .

A

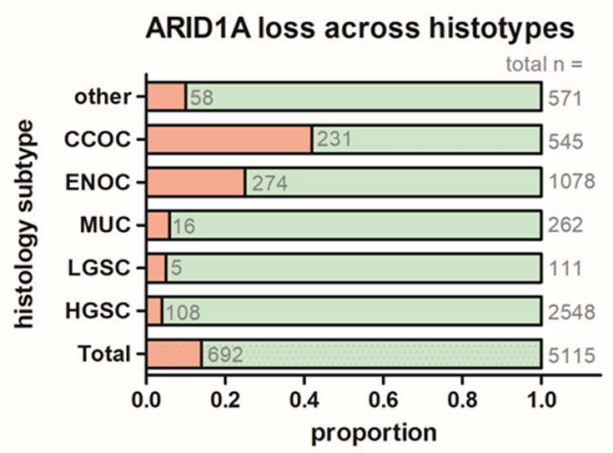

$\square$ absent/subclonal $\square$ present
B

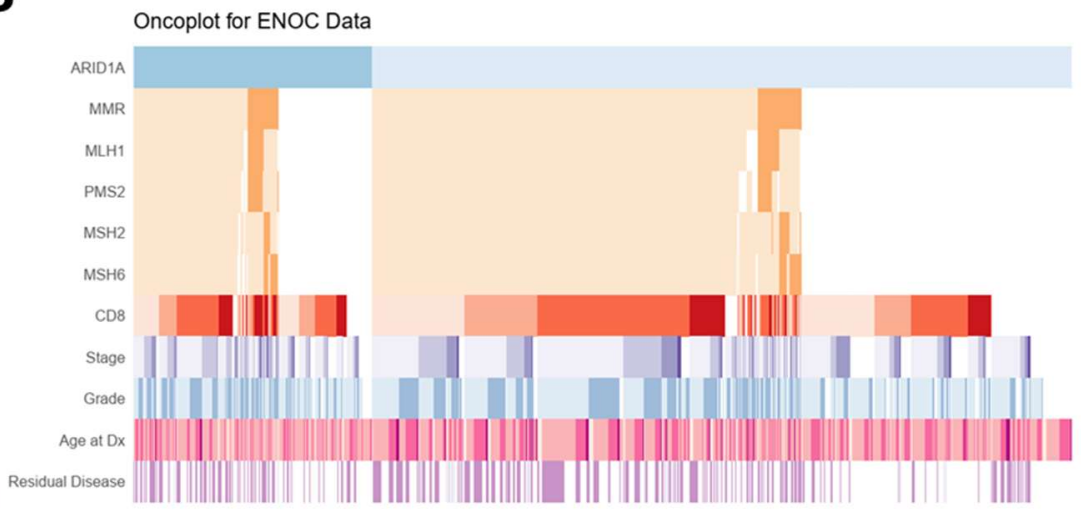

C

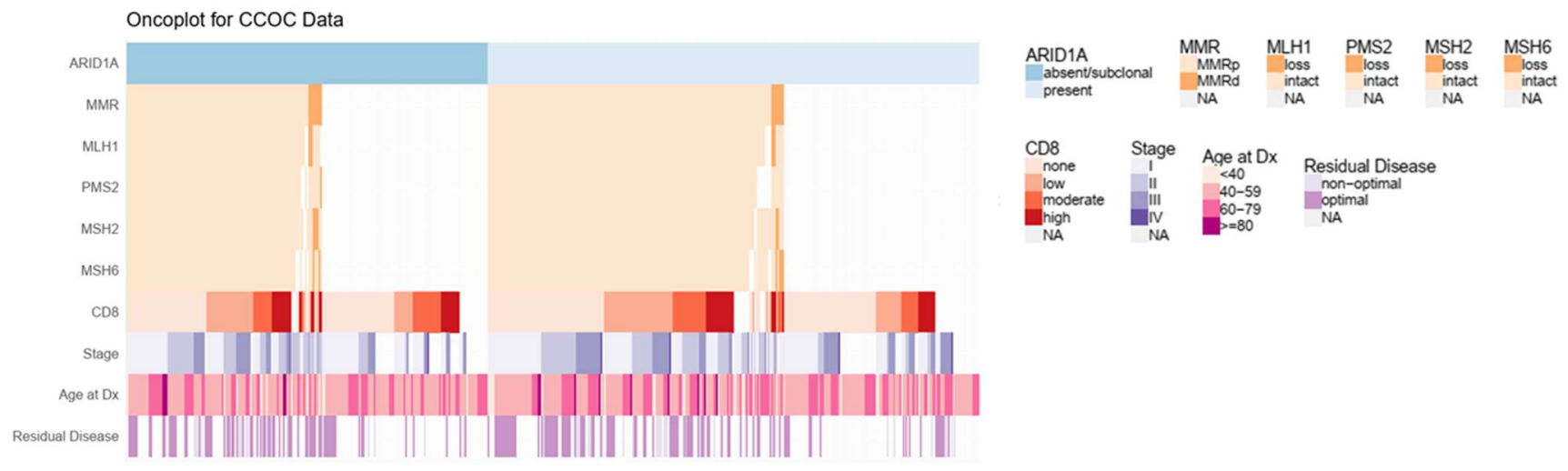

D

G

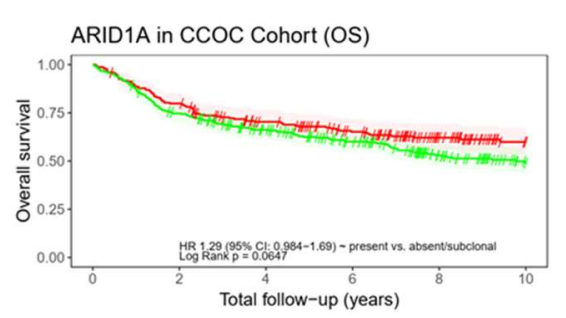

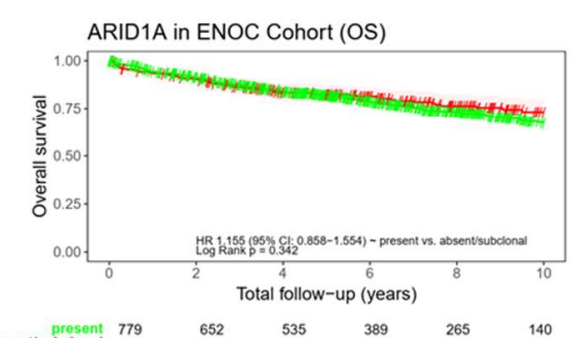

E

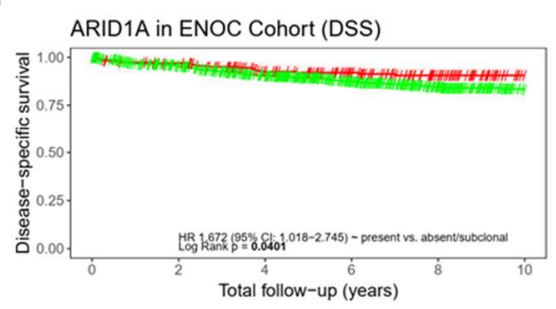

$\begin{array}{lllllll}\text { present } & 779 & 652 & 535 & 389 & 265 & 140 \\ \text { absentsubclonal } & 265 & 229 & 184 & 147 & 99 & 51\end{array}$
H

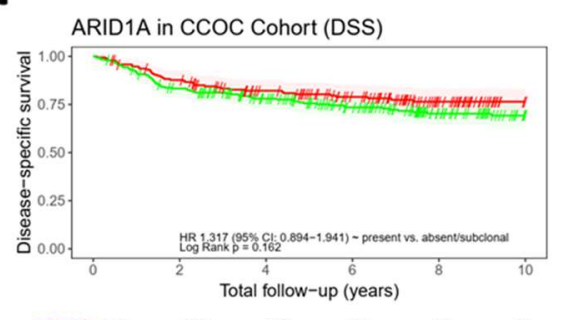

F

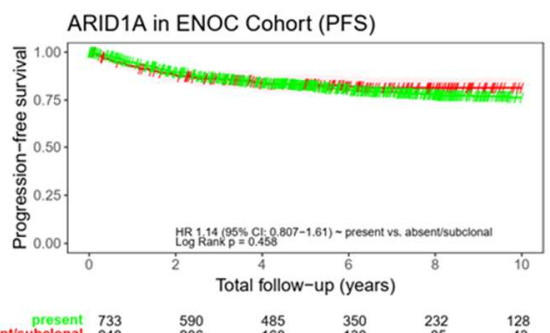

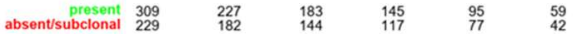

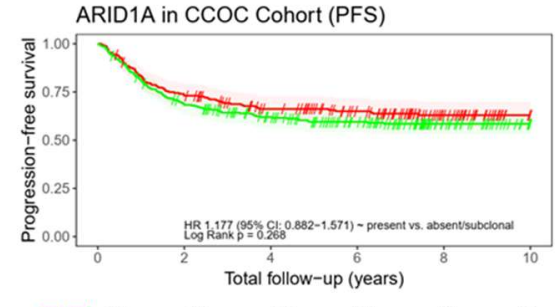

